\title{
ROLE MODEL FOR SYSTEMS ENGINEERING APPLICATION
}

\author{
Gräßler, Iris; Oleff, Christian; Hentze, Julian \\ Paderborn University - Heinz Nixdorf Insitute
}

\begin{abstract}
Twenty-three years ago, Sheard published a very well-known description of Systems Engineering roles. Each role represents and defines activities and tasks to be taken into account for performing Systems Engineering through the entire system life cycle. As today's more and more complex systems require different considerations and approaches, these activities and tasks have changed and thereby the description of the role model need to be updated. This work introduces the "Role Model for Systems Engineering Application", which is adapted to today's circumstances, with the intention to give practitioners guidance in applying Systems Engineering. For this purpose, results from literature as well as from research projects and industrial applications experience were analyzed and combined to an updated role description.
\end{abstract}

Keywords: Systems Engineering (SE), Design education, Design practice, SE Application, SE Role Model

\section{Contact:}

Oleff, Christian

Universität Paderborn - Heinz Nixdorf Insitut

Product Creation

Germany

christian.oleff@hni.upb.de

Cite this article: Gräßler, I., Oleff, C., Hentze, J. (2019) 'Role Model for Systems Engineering Application', in Proceedings of the 22nd International Conference on Engineering Design (ICED19), Delft, The Netherlands, 5-8 August 2019. DOI:10.1017/dsi.2019.132 


\section{INTRODUCTION}

System complexity is continuously increasing and has led to new (and different) challenges a Systems Engineer faces when developing highly complex systems (Haberfellner, 2012). Twenty-three years ago, Sheard published a very well-established description of Systems Engineering Roles (Sheard, 1996). Twelve roles a Systems Engineer needs to take into account in terms of effective application of Systems Engineering are distinguished. Each role represents and defines activities and tasks to be taken into account for performing Systems Engineering through the entire system life cycle (Walden et al., 2015). As today's more and more complex systems require different considerations and approaches, these activities and tasks have changed. The aim of this research is to show that the Systems Engineering Roles by Sheard have to be adapted to today's circumstances, with the intention to give practitioners a guidance in applying Systems Engineering. For this purpose, results from literature as well as from research and industrial applications were analysed and combined to an updated role model.

\subsection{Motivation}

Trends like digitalization and increasing complexity lead to changes in the working environment, engineering approaches and required competencies (Gräßler et al., 2018b; Gräßler et al., 2018a; Boston Consulting Group, 2015; BMWi, 2015). This demands for more Systems Engineering application, but also affects the approach of how to apply the methodology of Systems Engineering to industrial projects. Exemplary drivers are advanced technical possibilities in the fields of digitized cooperation, modelling and simulation. In consequence, proven models and approaches need to be evaluated and adapted to today's needs. In an industrial context, the application of Systems Engineering usually goes along with changes in the organizational structure and allocation of responsibilities (Gräßler et al., 2018b; Gräßler and Hentze, 2017a; Wenzel, 2003).

The twelve Systems Engineering Roles by Sheard (Sheard, 1996) are a useful and established starting point to guide the adjustments. The authors' experiences in industrial projects show that the effort to match the company needs and individual role descriptions with the twelve theoretic Systems Engineering Roles by Sheard increased and can lead to confusion and misunderstandings between Systems Engineers and classic product developers.

New challenges and tasks, e.g. the upcoming needs for technical systems security, digitized and individualized systems, need to be incorporated and demand for new thinking. The importance of some roles grew substantially and needs to be exposed and explained in more detail. Other challenges show lower relevance by the time and should be conflated. Although the findings of Sheard are still considered as valid, a rebalancing of their importance and integration of new aspects in a new role description is necessary. Especially, since this research has a close linkage to needs of the industrial application of Systems Engineering in different branches and sizes of companies. An up-to-date role model that considers the industrial application demands can help to spread the ideas and the approach of Systems Engineering.

\section{STATE OF THE ART}

Systems Engineering is defined as a structured cross-disciplinary approach for the development of complex technical systems to achieve a cross-disciplinary optimum in a specified time frame and budget (Gräßler, 2015). This definition represents the ideas and principals of the approach. Particularly, emphasis has to be drawn on cross-disciplinarity, frontloading, that describes the focus on early stages of the development process, and consideration of technical as well as organizational and managerial tasks (Gräßler and Hentze, 2017b). Systems Engineering comprises a holistic approach, which deals with all stages of the life cycle of the System of Interest (SOI) (Haberfellner, 2012; Gräßler et al., 2018b). It is based on Systems Thinking, which includes the clear definition of the system, its elements, its connections and the separation from the environment by definition of boundaries (Haberfellner, 2012; Walden et al., 2015; Arnold and Wade, 2015; van Bertalanffy, 2003; Churchman, 1984; Gräßler et al., 2018b).

For the application of Systems Engineering, it is necessary to configure the theoretical approaches e.g. (U.S. Department of Transportation, 2009; National Aeronautics and Space Administration, 2007; United States Department of Defense, 2001) to each case's specific circumstances. This adaption is 
called tailoring and means to transfer a holistic approach into a practical application on an organizational or project level (Walden, 2015). In order to apply Systems Engineering, companies need to adapt their processes, organizational structure, role definition and project responsibilities. Although Systems Engineering roles have to be determined as appropriate, reference models can be a useful baseline. A frequently cited description of Systems Engineering roles are the twelve roles of Systems Engineering by Sheard (Sheard, 1996); Figure 1). In most cases those roles should be addressed during a Systems Engineering project at some point of time (Sheard, 1996).

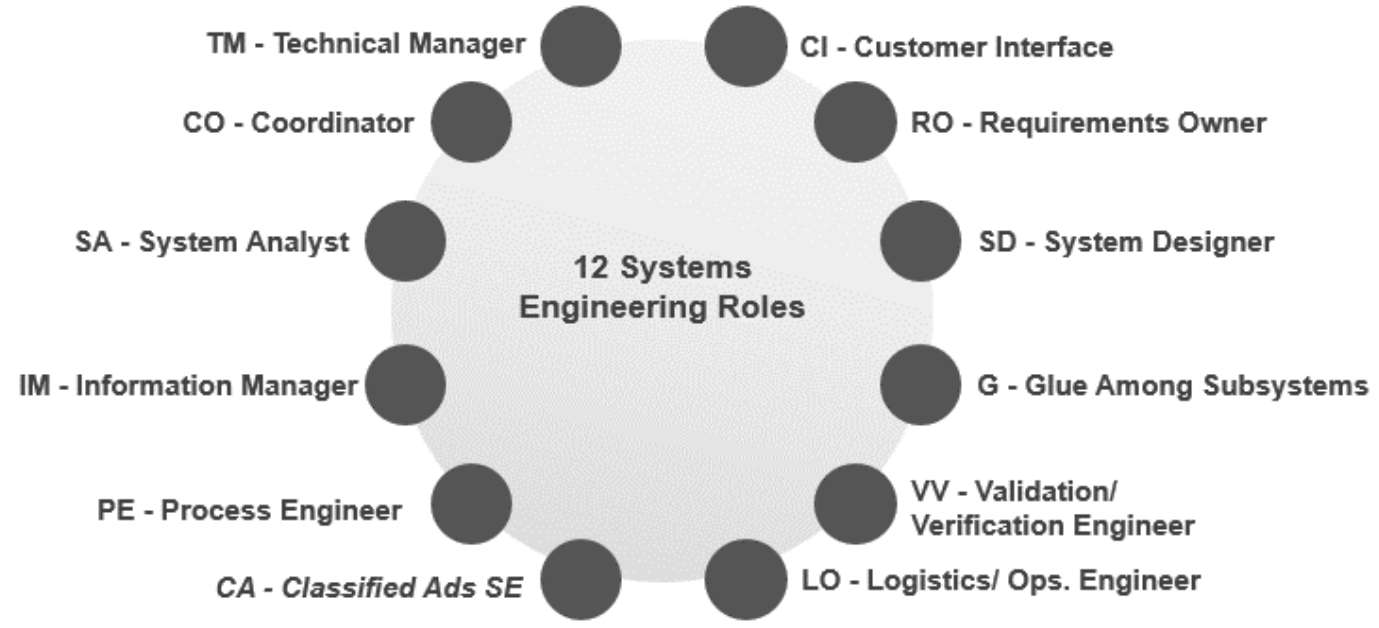

Figure 1: Twelve Systems Engineering Roles (Sheard, 1996)

\section{APPROACH}

Starting point of research are the twelve Systems Engineering Roles described by Sheard (Sheard, 1996). As mentioned, it gives a profound insight into the challenges a Systems Engineer faces in a Systems Engineering project. A comparison with five well-established SE competency models (INCOSE UK, 2010; INCOSE, 2018; Trudeau/Ziarko, 2007; NASA, 2009; BKCASE Editorial Board, 2017)) was carried out. Based on the information and knowledge about role models of Sheard and basic literature on Systems Engineering approaches, different industry projects were conducted, aiming at a consistent role description according to the individual needs of the companies. This includes to perform Systems Engineering without losing the established structure of a well-working company during reorganization. In this context, the twelve Systems Engineering Roles by Sheard were adapted to the individual company's needs and structure.

Implications for this work are based on the authors' experience from numerous industrial application projects during the last years as well as the scientific exchange and cooperation with Systems Engineering practitioners and researchers. A survey on which Systems Engineering competences are needed in an industrial and academic context, published at the 13th IEEE International System of Systems Engineering Conference (SoSE) 2018 in Paris (Gräßler et al., 2018b), came with these research activities to receive a broad range of feedback to support and underline the results. The aim of the survey was to identify major challenges of applying Systems Engineering in an industrial context. 25 practitioners from different branches answered the questionnaire and gave profound insight into the industrial perspective on Systems Engineering competencies.

An overview on the overall approach is given in Figure 2. One particular industrial project with major impact on this research is pointed out for this publication. It was conducted in year 2015 with a big size automotive company (>100.000 employees) headquartered in Germany and intended to implement a corporate Systems Engineering Education Program, meant to be a flagship project for the whole company. Therefore, the organization structure and responsibilities needed to be consolidated, extended and rearranged in order to fit today's demands of effective and efficient Systems Engineering application. 


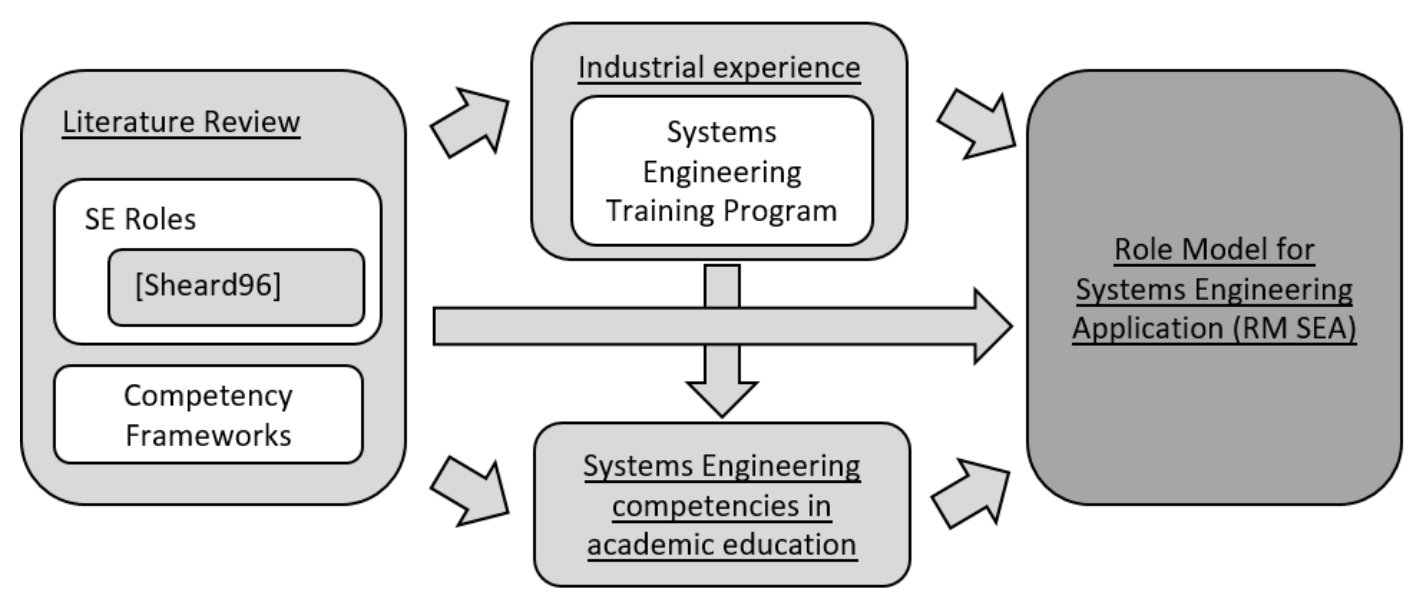

Figure 2: Development of "Role Model for Systems Engineering Application" (RM-SEA)

\section{ROLE MODEL FOR SYSTEMS ENGINEERING APPLICATION (RM-SEA)}

For the conception of the new RM-SEA role model, all findings and experiences were discussed, tailored, extended and concretised based on the state of the art. The retransfer of results from industrial practice into a theoretical and generic role model description is thereby an important part. Systems Engineering fundamentals e.g. system thinking, consideration of the whole lifecycle and interdisciplinary collaboration is the basis for understanding the roles. The roles describe possible and frequent activities and tasks in Systems Engineering projects, but not the theoretical foundations and ideas of all known Systems Engineering approaches. In the following sections, the thirteen new Systems Engineering roles are introduced and described in detail. An overview is given at the end of this section in Figure 3.

\subsection{Modelling engineer}

This role is based on the following references: (INCOSE, 2018; Walden et al., 2015; Sheard, 1996; INCOSE UK, 2010). First, it is important to clarify that modelling is more than just a Systems Engineering method. It is a core element of Systems Engineering and represents a conflation of several Systems Engineering principles. Not only a holistic perspective and consideration of system interfaces (Sheard, 1996; INCOSE UK, 2010), but also the top-down (decomposition) and bottom-up (integration) thinking and the continually verification \& validation based on traceability. Modelling became more and more important for the application of Systems Engineering. Two independent developments can be seen as its root cause. On the one hand, the preconditions to perform digital modelling are fulfilled by higher performance of computers and several years of software experience that have led to high quality modellingsoftware (Abramovici and Herzog, 2016). On the other hand, the need to represent a system with different kinds of models grew stronger (Abramovici and Herzog, 2016). Due to a heavy increase of system complexity, bringing together different disciplines and developing a high-quality system is becoming more and more challenging. The overall goal of a Modelling Engineer is to represent all relevant aspects of a system within an adequate model (INCOSE, 2018). This includes the system elements, behaviour and properties, but also its internal and external interfaces and the environment (Weilkiens, 2014). Furthermore, the Modelling Engineer must deduce important information from the ensemble of models and make it useable for further development activities and decision processes. Hence, it is essential to keep the system representations continuously up to date, correct and consistent.

A Modelling Engineer needs to evolve an in-depth system understanding and simultaneously keep a holistic perspective on the system -both important attributes of Systems Thinking- to deduce information for decision making (see Technical Manager) and development activities. The Modelling Engineer furthermore serves as the primary information source in case of development anomalies, due to the ability to assess the impact of counter-actions best (Sheard, 1996).

\subsection{System architect}

This role is based on the following references: (INCOSE UK, 2010; BKCASE Editorial Board, 2017; NASA, 2009; INCOSE, 2018; Sheard, 1996; Gräßler et al., 2018a; VDI, 2004). Basis for the role 
System Architect is the role "System Designer" introduced by Sheard. Lately more attention was put on a differentiation between system architecture and system design, as described in INCOSE Handbook V4 (Walden et al., 2015). INCOSE emphasizes that it is necessary to distinguish between an abstract and concept oriented system architecture and a technology oriented system design (Walden et al., 2015). Although Sheard called it "System Designer" the tasks mostly overlap with the System Architect introduced in this work.

Being responsible for creating the system architecture (Sheard, 1996), the System Architect needs to identify different solution candidates and select the most promising one in cooperation with the Technical Manager (Sheard, 1996). This is based on technical considerations (e.g. feasibility studies) as well as economical ones (e.g. risk analysis) (BKCASE Editorial Board, 2017). Although, the System Architect's main focus is on the high-level system architecture, a logical decomposition of the system and definition of subsystems is still part of this role (NASA, 2009; Sheard, 1996). This also applies to activities and tasks of system design. The System Architect is involved in high-level design decision, but does not extensively perform detailed domain specific design. This is responsibility of the domain-experts, following the decomposition of the V-model (Gräßler et al., 2018a; VDI, 2004). Holding such a core role, it is required to closely interact with the Requirement Engineer and ensure that the system architecture and design will allocate and fulfil all requirements. Especially in terms of Software Systems Engineering this role is of major relevance, because the architecture creates the main added value compared to hardware development, for which the added value is created during the implementation on a lower decomposition level (BKCASE Editorial Board, 2017).

\subsection{System interface manager}

This role is based on the following references: (Kossiakoff and Sweet, 2005; Walden, 2007; INCOSE UK, 2010; BKCASE Editorial Board, 2017; NASA, 2009; Sheard, 1996; INCOSE, 2018). The overall responsibility of the System Interface Manager is to harmonize the different system elements and create an overall optimum (BKCASE Editorial Board, 2017), which is superior to the performance of each element on its own (Kossiakoff and Sweet, 2005). The System Interface Manager is responsible to deal with this challenge and in case of an ongoing increase of system complexity this role will become even more demanding and important for Systems Engineering success.

Today the maturity of many technologies is on a high level. This is a barrier for organizations to develop and produce new technological solutions and favour commercial off-the-shelf components (COTS) instead (Walden, 2007). As a consequence, the Systems Engineer increasingly harmonizes and incorporates predefined elements instead of initiating the development of synergized elements. Kossiakoff calls this COTS-Based Systems Engineering (Kossiakoff and Sweet, 2005).

\subsection{Technical manager}

This role is based on the following references: (BKCASE Editorial Board, 2017; Kossiakoff and Sweet, 2005; Walden et al., 2015; INCOSE UK, 2010; INCOSE, 2018; Sheard, 1996; NASA, 2009). At its core, the Technical Manager is responsible for technology based decisions regarding the System of Interest (NASA, 2009). The Technical Manager needs to understand, evaluate and select candidate technical solutions on different levels of detail and based on appropriate technical measures (NASA, 2009; BKCASE Editorial Board, 2017; INCOSE, 2018). On the one hand, both broad and deep knowledge about the included domains is needed (Kossiakoff and Sweet, 2005). On the other hand, the Technical Manager needs to increase the available information basis by strongly involving other Systems Engineering roles.

Due to globalization, the size of development teams is increasing, the team members come from different countries and might even work at different locations. It is the responsibility of the Technical Manager to coordinate efforts, align them with the overall goal and match their knowledge and skills. By representing the project hub, this role should also proactively identify problems and prevent them (Sheard, 1996). Such problems can be either technical, organizational or personal.

\subsection{Leader}

This role is based on the following references: (Kossiakoff and Sweet, 2005; INCOSE, 2018; Sheard, 1996; Trudeau/Ziarko, 2007; BKCASE Editorial Board, 2017). The role Leader focuses on how to inspire employees involved in the Systems Engineering project and delegating work according to their strength 
and weaknesses. This role requires high leadership and coordination skills (Kossiakoff and Sweet, 2005; INCOSE, 2018; Sheard, 1996) in order to perform a situational and flexible leadership style that factors in the characters and the given circumstances. The Leader ensures that decisions are forward-looking and the result of seeking a win-win solution. The role brings new and innovative approaches into the team, supports their motivation and makes them focusing on the overall project success instead of solo runs. At the same time the Leader serves as a coach and mentor and sets good examples for the development team in terms of work ethics (INCOSE, 2018; BKCASE Editorial Board, 2017).

\subsection{Stakeholder interface manager}

This role is based on the following references: (Sheard, 1996; Walden, 2007; Kossiakoff and Sweet, 2005; Walden et al., 2015; INCOSE UK, 2010; BKCASE Editorial Board, 2017; NASA, 2009; INCOSE, 2018; Trudeau/Ziarko, 2007). The role Stakeholder Interface Manager is the basic element of project success. To ensure stakeholder satisfaction, it is essential to adequately elicit, define and understand their needs and transform them into requirements afterwards (Walden et al., 2015). It is the responsibility of the Stakeholder Interface Manager to keep the set of requirements consistent to stakeholder needs (Sheard, 1996). This is a continuous task, since it has to be ensured that the most recent needs are reflected by the requirements and that changes are implemented thoroughly. To do so, this role represents the customer point of view within the project (Sheard, 1996). Furthermore, stakeholder relationships have to be fostered in order to provide a basis for agile engineering. Only preformed knowledge of stakeholders' interests enables an agile approach to be effective and efficient. Complementary to this, it is also part of the role Stakeholder Interface Manager to communicate and justify project decisions, issues, rationales and limitations towards the stakeholders (Walden et al., 2015). Based on this, the engineer needs sufficient technical Know-How. Paired with negotiation and social skills to align stakeholder interests, solve trade-offs and to work out further actions. This includes all kinds of interactions with the customer, from project initiation till the end of the system life cycle (e.g. negotiations and support). As distinct from marketing roles etc. the Stakeholder Interface Manager is only focused on technical aspects.

\subsection{Requirements engineer}

This role is based on the following references: (Walden, 2007; INCOSE UK, 2010; BKCASE Editorial Board, 2017; NASA, 2009; Sheard, 1996; INCOSE, 2018; Gräßler et al., 2018e, 2018e; Gräßler et al., 2018c; Walden et al., 2015). The Requirements Engineer is concerned about one or several requirements from all stages (stakeholder needs, stakeholder requirements, system requirements) of a Systems Engineering project. It is part of this role to ensure, that all requirements are consistent with the higher-level and lower-level requirements (Walden, 2007). This is very challenging in case of changes affecting the overall system or even subsystems (Gräßler et al., 2018e). The Requirements Engineer needs to assess the change impact and identify all requirements that correspondingly need to be modified (Gräßler et al., 2018d). Furthermore, it is the responsibility of this role to interact with the System Architect and guarantee that the system design fulfils the requirement set. To do so, the requirements need to be formulated according to common standards (Walden et al., 2015).

\subsection{Life cycle engineer}

This role is based on the following references: (Walden et al., 2015; INCOSE UK, 2010; Trudeau/Ziarko, 2007; INCOSE, 2018; Sheard, 1996). The main responsibility of a Life Cycle Engineer is to implement a holistic life cycle perspective into all decisions on each level of the system, including very detailed developments of small parts and elements (Trudeau/Ziarko, 2007). Especially the introduction and communication of relevant restrictions and boundary conditions from all system life cycle phases is a core activity of the Life Cycle Engineer (INCOSE UK, 2010; INCOSE, 2018). The Life Cycle Engineer also encourages Design for X thinking (INCOSE UK, 2010; INCOSE, 2018). Exemplary, this targets aspects like sustainability, transition, system integrity or public perception.

\subsection{Implementation engineer}

This role is based on the following references: (INCOSE, 2018; Trudeau/Ziarko, 2007; NASA, 2009; $B K C A S E$ Editorial Board, 2017b3). In the first place, the Implementation Engineer is responsible to coordinate and execute the realization of all system elements according to the architecture and design 
specifications. This role needs to have a hands-on mentality and high social skills to include team members from all necessary disciplines. Also the ability to work in a highly iterative and parallel manner according is required to perform this role successfully. The Implementation Engineer also brings in a practical perspective. Especially during requirement definition, architecture selection and design elaboration, this role focuses on the identification and removal of impractical or costly choices. This is mostly based on knowledge and experiences regarding implementation methods and procedures.

\subsection{Validation and verification engineer}

This role is based on the following references: (Kossiakoff and Sweet, 2005; INCOSE UK, 2010; INCOSE, 2018; BKCASE Editorial Board, 2017; NASA, 2009; Sheard, 1996). The Validation and Verification Engineer facilitates stakeholder satisfaction. This role is responsible for measuring system performance on the one hand (Verification) and stakeholder needs fulfilment on the other hand (Validation). To do so, this role needs to plan and implement the verification and validation actions (Sheard, 1996). The development of V \& V strategies is just as much part of the work as the execution of tests, measurements or getting in contact with the customer. The Validation and Verification Engineer should interact with the Requirements Engineer closely to ensure that the fulfilment of requirements is measured appropriately and goes hand in hand with stakeholder satisfaction.

\subsection{Security engineer}

This role is based on the following references: (Trudeau/Ziarko, 2007; INCOSE, 2018; Walden et al., 2015). Due to the rising digitalization of products and processes as well as the enhancement of numerous mechatronic systems to Cyber Physical Systems, the security perspective on the entire technical system of interest has to be reinforced. Especially the interplay between the involved disciplines is a major challenge for developing secure technical systems, since weaknesses in cross disciplinary interfaces are of high risk. The Security Engineer ensures that protection considerations are given a proper weight in decision making on all levels of detail and take into account security issues across the whole life cycle (Walden et al., 2015). Therefore, the Security Engineer needs to raise awareness amongst all development team members to this issue and foster certification and accreditation. Secure engineering often deals with trade-offs, it is responsibility of this role to solve such trade-offs and create a balance between risks and opportunities (INCOSE, 2018; Trudeau/Ziarko, 2007). Since the importance of Security Engineering will rise, it is introduced as a new role

\subsection{Process owner}

This role is based on the following references: (Sheard, 1996; INCOSE UK, 2010; Trudeau/Ziarko, 2007; Gräßler et al., 2018b; INCOSE, 2018). This role is responsible to define, implement, control, evaluate and modify SE related processes within the organization. Beside the articulated importance of this role from practitioners, the survey on Systems Engineering competencies gives prove for it (Gräßler et al., 2018b). Participants emphasized the importance of theory based Systems Engineering knowledge, which is the basis for defining and managing SE processes. The before mentioned task is directly linked to tailoring. The Process Owner selects required processes and adapts them to organizational and project needs. This includes considerations on concurrent and agile engineering (INCOSE, 2018). Especially on the project level, the Process Owner needs to cooperate closely with the Technical Manager since this role has sufficient knowledge about the project specifics. Together they need to define processes that support a successful project execution. Lastly, the Process Owner needs to ensure, that the processes are aligned to todays need of constant preparedness of integrating changes. These changes can arise from stakeholders or the organization itself. Either way the changes need to be realized in an effective and efficient manner. For this, sufficient processes are needed. In total, the Process Owner is crucial to obtain an overall understanding of SE activities and ensure high quality SE processes that support organization and project success.

\subsection{Configuration manager}

This role is based on the following references: (INCOSE, 2018; INCOSE UK, 2010; Walden et al., 2015; BKCASE Editorial Board, 2017; NASA, 2009). The role Configuration Manager focuses on all kinds of outputs like artefacts, objects or documents. The term "output" needs to be understood extensively in this context. It includes process and project outputs on all levels of detail. This includes 
both, interim and final outputs. Interim outputs represent all results that lead to a higher-level output. A core activity of the Configuration Manager is to make outputs available for concerned parties. Therefore, this role needs to maintain the topicality and correctness of the overall set of outputs, to support further usage and avoid errors. Furthermore, the Configuration Manager ensures that System Integrity is considered at all decision points. This means that the approval of every output needs to take into account the technical (product), business (business case) and budget (funding) aspects equally (Walden et al., 2015). If there is an imbalance between these aspects, the Configuration Manager needs to interfere and remediate the decision. Due to the scope of this task, it is very important that there is a constant cooperation of this role with the Process Owner and Information Manager. To ensure high quality of outputs, adequate processes and information are crucial.

\subsection{Information manager}

This role is based on the following references: (Walden et al., 2015; Kossiakoff and Sweet, 2005; BKCASE Editorial Board, 2017; NASA, 2009; INCOSE, 2018; Sheard, 1996; Walden et al., 2015; Weilkiens, 2014). The Information Manager ensures high quality of all kind of information and makes information available to concerned stakeholders. First of all the Information Manager needs to have a holistic perspective and sound understanding of the system to collect and edit relevant information from different disciplines, select concerned parties and make relevant information available to them. Thereby the Information Manager is a key role to facilitate an overall optimum of project outputs. The holistic perspective requires to not just have discipline specific knowledge and the ability to identify relevant information, but also to consider interfaces and their influences on the system (Walden et al., 2015). Today's Information Manager also needs to cooperate with the Modeling Engineer closely, since much information about the system itself and its environment is visualized by different system models (Weilkiens, 2014). In consequence, the Information Manager supports effective and efficient cooperation of all disciplines and ensures holistic and high quality decision making.

\subsection{Entrepreneur}

This role is based on the following references: (Trudeau/Ziarko, 2007; BKCASE Editorial Board, 2017; INCOSE UK, 2010). The Entrepreneur takes a superordinate perspective and initiates thinking about business aspects like costs, pricing and rates. This also includes financial reporting and metrics, to foster a transparent project execution and an ongoing internal support from company leadership. The Entrepreneur also spreads a sense of responsibility among the team and the courage to bold decisions. The role also takes care of important activities, which are not directly part of the value chain, like internal or external negotiations and supplier management. Additionally, this role does push forwards the team and imparts endurance in difficult situations jointly with the Leader.

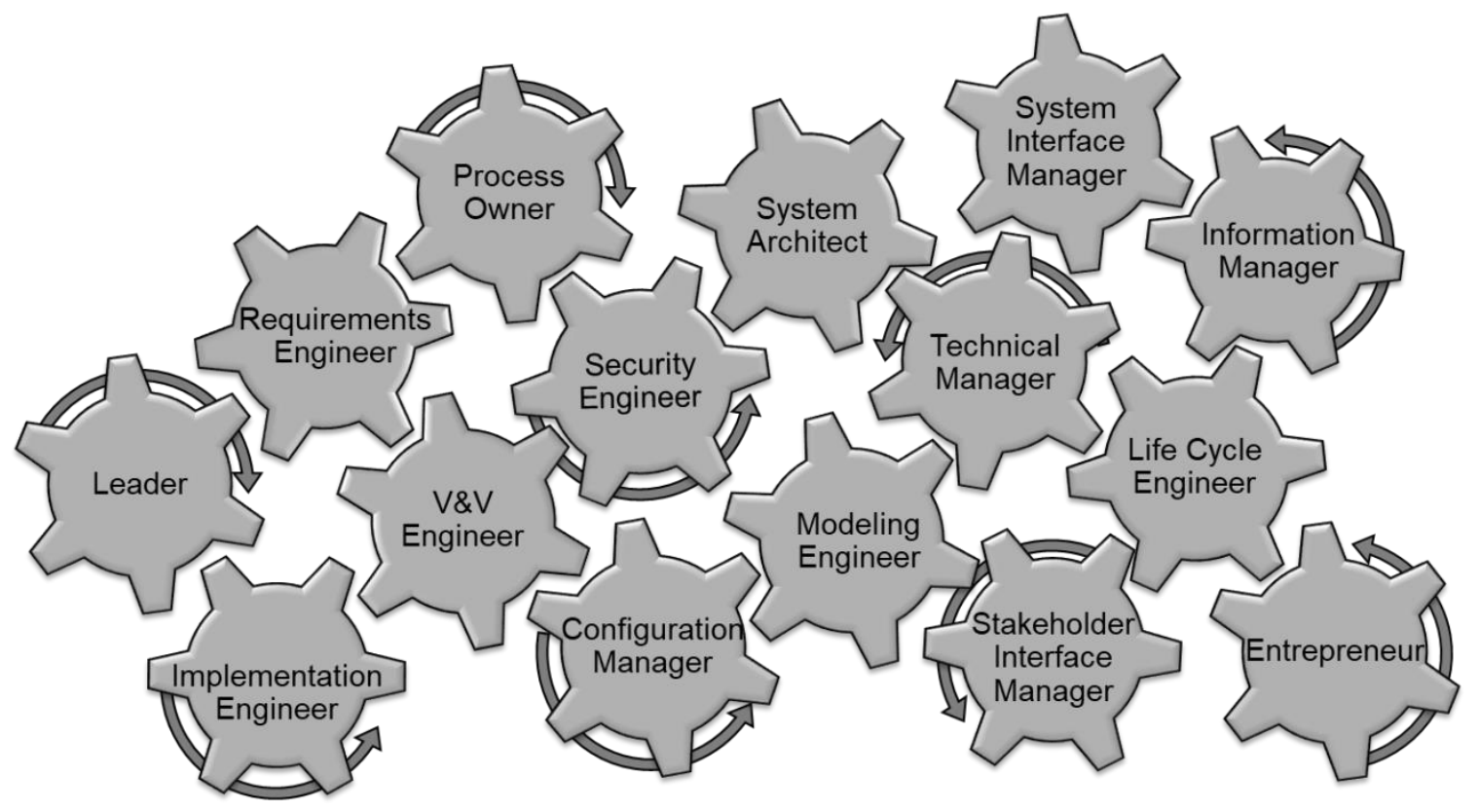

Figure 3: Role Model for Systems Engineering Application (RM-SEA) 


\section{APPLICATION}

The presented new RM-SEA role model is meant to be used as a reference for Systems Engineering application. Companies usually need to change their organizational structure to incorporate the "Systems Engineer" according to the roles described in the new role model. The rising need for Systems Engineering competencies and application can lead to opposition from traditional roles within the organization. The role model can take some of the tension out of the situation by providing a detailed overview of the Systems Engineering roles needed to perform Systems Engineering and what their responsibilities should be and should not be. Then, theses role are matched with the established organizational structure and required changes can be identified. As part of the tailoring process, these changes are implemented. It should be noticed that not all of these roles are equally important for every organization or project and in the course of time. According to this, some role might be merged, but the authors agree with a statement from Sheards (Sheard, 1996): "No one person will perform all [thirteen] roles at once [...]."

By the time, the organizational structure might change. It should be checked, whether the organizational structure still fits the above-described roles and their responsibilities, to ensure sustainability, effectiveness and efficiency of the Systems Engineering application. The above considerations are also valid for reforming an implemented Systems Engineering approach within a company and for project specific Systems Engineering application.

\section{CONCLUSION AND OUTLOOK}

We expect the proposed new Role Model for Systems Engineering Application (RM-SEA) to enable companies from different branches and sizes to implement Systems Engineering more easily and more efficiently. The updated overview of Systems Engineering roles provides an adequate reference point for company or project specific tailoring and by including today's state of the art, reduces conflicts and fuzzy overlaps between Systems Engineers and conventional product developers. Experiences from developing the Systems Engineering Training Program at a large company support this statement. Although the role model is developed with a lot of knowledge and experience from different industrial companies, it is important to spread the RM-SEA to a wide range of industrial companies with different sizes, branches and countries. Compared to the 12 Systems Engineering Roles by Sheard, there was a shift in importance from design towards modeling activities. Furthermore, the authors introduced the roles Leader, Life Cycle Engineer, Implementation Engineer, Security Engineer, Configuration Manager and Entrepreneur to encourage effective interdisciplinary collaboration, sustainable and secure system's performance and structured but open-minded thinking. The authors explicitly do not include a role like Classified Ads (Sheard, 1996), that represents "other". In our opinion, the role model gives a reference. It is not possible to constitute all Systems Engineering roles and therefore modification based on individual needs are considered as part of the tailoring effort and should not be represented in the role model.

The presented new RM-SEA provides the opportunity that practitioners can deduce the roles and competences needed for their individual circumstances and thereby facilitates Systems Engineering understanding, acceptance and application as a whole.

\section{REFERENCES}

Abramovici, M. and Herzog, O. (Eds.) (2016), Engineering im Umfeld von Industrie 4.0: Einschätzungen und Handlungsbedarf, Acatech Studie, acatech; Herbert Utz Verlag GmbH, München, München.

Arnold, R.D. and Wade, J.P. (2015), "A definition of systems thinking. a systems approach", Procedia Computer Science, Vol. 44, pp. 669-678, http://doi.org/10.1016/j.procs.2015.03.050.

BKCASE Editorial Board (2017), Guide to the Systems Engineering Body of Knowledge (SEBoK): v1.8.

BMWi (Ed.) (2015), Industrie 4.0 und Digitale Wirtschaft: Impulse für Wachstum, Beschäftigung und Innovation, April 2015, Bundesministerium für Wirtschaft und Energie - Referat Öffentlichkeitsarbeit, Berlin.

Boston Consulting Group (Ed.) (2015), Industry 4.0: The future of productivity and growth in manufacturing industries. Gefälligkeitsübersetzung: Industrie 4.0: Die Zukunft der Produktivität und des Wachstums in verarbeitenden Industrien.

Churchman, C.W. (1984), The Systems Approach, Rev. and updated, 2. Laurel print, Laurel Book, New York, NY. 
Gräßler, I. (2015), “Umsetzungsorientierte Synthese Mechatronischer Referenzmodelle. ImplementationOriented Synthesis of Mechatronic Reference Models", In: Bertram, T. (Ed.), Konferenzband der VDI Mechatronik: Fachtagung Mechatronik 2015, Dortmund, pp. 167-172.

Gräßler, I. and Hentze, J. (2017a), “Application potentials of systems engineering for small and middle-sized enterprises", Paper Presented at 11th CIRP Conference on Intelligent Computation in Manufacturing Engineering (ICME), 19.-21.07.2017, Ischia, http://doi.org/10.1016/j.procir.2017.12.253.

Gräßler, I. and Hentze, J. (2017b), "Enriching Mechatronic V-Model by Aspects of Systems Engineering”, In: Araujo, A. and Mota Soares, C.A. (Eds.), Smart Structures and Materials, Springer International Publishing, Basel, pp. 80-86.

Gräßler, I., Hentze, J., Bruckmann, T. and Graessler, I. (2018a), "V-models for interdisciplinary systems engineering”, Paper Presented at DESIGN Conference, 21.-24.05.2018, Dubrovnik, http://doi.org/10.21278/idc.2018.0333.

Gräßler, I., Hentze, J. and Oleff, C. (2018b), "Systems engineering competencies in academic education. An industrial survey about skills in systems engineering", Paper Presented at 13th System of Systems Engineering Conference, 19.-22.06.2018, Paris, available at: https://ieeexplore.ieee.org/document/8428741/ (accessed 13 August 2018), http://doi.org/10.1109/SYSOSE.2018.8428741.

Gräßler, I., Oleff, C. and Scholle, P. (2018c), "Methode zur Bewertung von Anforderungsänderungen additiv gefertigter Produkte”, In: Krause, D., Paetzold, K. and Wartzack, S. (Eds.), Design for X: Beiträge zum 29. DfX-Symposium, Tutzing, 25./26. September 2018, TuTech Innovation, Hamburg, pp. 333-344.

Gräßler, I., Oleff, C. and Scholle, P. (2018d), "Methode zur Bewertung von Anforderungsänderungen additiv gefertigter Produkte”, In: Krause, D., Paetzold, K. and Wartzack, S. (Eds.), Design for X: Beiträge zum 29. DfX-Symposium, Tutzing, 25./26. September 2018, TuTech Innovation, Hamburg, pp. 333-344.

Gräßler, I., Scholle, P., Hentze, J. and Oleff, C. (2018e), "Semi-automatized assessment of requirement interrelations", Paper Presented at DESIGN Conference, 21.-24.05.2018, Dubrovnik, available at: https://doi.org/10.21278/idc.2018.0298, http://doi.org/10.21278/idc.2018.0298.

Haberfellner, R. (2012), Systems Engineering: Grundlagen und Anwendung, Vol. 12., völlig neu bearb. und erweiterte Aufl, Orell Füssli, Zürich.

INCOSE (2018), Systems Engineering Competency Framework.

INCOSE UK (2010), "Systems engineering competency framework”, available at: http://www.incoseonline.org.uk/Program_Files/Publications/zGuides_6.aspx?CatID=Publications (accessed 29-Aug-18).

Kossiakoff, A. and Sweet, W.N. (2005), Systems Engineering Principles and Practice: Principles and Practices, Wiley Series in Systems Engineering and Management, Wiley, Hoboken, NJ, http://doi.org/10.1002/0471723630.

NASA (2009), "Project management and systems engineering competency model. Academy of Program/Project \& Engineering Leadership (APPEL)”, available at: https://appel.nasa.gov/career-resources/competencymodel/ (accessed 11 October 2018).

National Aeronautics and Space Administration (2007), Systems Engineering Handbook, Rev1, Washington D.C.

Sheard, S.A. (1996), “Twelve systems engineering roles”, Paper Presented at Sixth Annual International Symposium, 7.-11. Juli, Marriot Copley Place Hotel, Boston, Massachusetts, USA.

Trudeau/Ziarko (2007), MITRE Institute SE Competency Model.

U.S. Department of Transportation (2009), Systems Engineering Guidebook for Intelligent Transportation Systems: Version 3.0.

United States Department of Defense (2001), Systems Engineering Fundamentals, Fort Belvour, Virginia.

van Bertalanffy, L. (2003), General System Theory: Foundations, Development, Applications, Rev. ed., 14. paperback print, Braziller, New York.

VDI (2004), Design Methodology for Mechatronic Systems - VDI 2206 No. 2206, Verein Deutscher Ingenieure, Düsseldorf, available at: www.vdi.de.

Walden, D.D. (2007), "The changing role of the systems engineer in a System of Systems (SOS) environment", in 1st Annual IEEE Systems Conference, 2007: Honolulu, HI, 9-13 April 2007, Honolulu, HI, USA, 09.04.2007-13.04.2007, IEEE Service Center, Piscataway, NJ, pp. 1-6, http://doi.org/10.1109/SYSTEMS.2007.374665.

Walden, D.D. (2015), "INCOSE systems engineering handbook: A guide for system life cycle processes and activities".

Walden, D.D., Roedler, G.J., Forsberg, K., Hamelin, R.D. and Shortell, T.M. (2015), Systems Engineering Handbook: A Guide for System Life Cycle Processes and Activities, 4th ed., Wiley.

Weilkiens, T. (2014), Systems Engineering mit SysML/UML: Modellierung, Analyse, Design, 3rd ed., dpunkt, Heidelberg, Neckar.

Wenzel, S. (2003), Organisation und Methodenauswahl in der Produktentwicklung, Systems Engineering, Utz, Wiss., München. 